\title{
Development of Stability Indicating Densitometric and Enhanced Sensitivity Spectrofluorimetric Methods for Determination of Zaleplon in Presence of its Acidic Degradation Products
}

\section{Sawsan A Abdel Razeq ${ }^{1}$, Suzan M Soliman² and Amal S Mohamed ${ }^{2 *}$}

${ }^{1}$ Analytical Chemistry Department, Faculty of Pharmacy (Girls), Al-Azhar University, Cairo, Egypt

${ }^{2}$ National Organization for Drug Control and Research (NODCAR). 6 Abu Hazem Street, Pyramids Ave. P. O. Box 29.Giza, Egypt

\begin{abstract}
Zaleplon is easily degradable into its acidic degradation products, so two stability- indicating methods were developed for determination of zaleplon in the presence of these degradation products and are successfully applied to quantify zaleplon in pharmaceutical preparations. The first was a densitometric evaluation of thin-layer chromatograms of the drug using a mobile phase of ethyl acetate - ammonia (33\%) - methanol $(8.5: 0.5: 1, \mathrm{v} / \mathrm{v} / \mathrm{v})$. The chromatograms were scanned at $338 \mathrm{~nm}$, a wavelength at which zaleplon can be readily separated from its degradation products and determined in the range of $0.5-2.5 \mu \mathrm{g} / \mathrm{sppot}$ with mean percentage recovery of 100.79 $\pm 0.65 \%$. The second method was based on measuring the fluorescence intensity of zaleplon at $\lambda_{\mathrm{ex}} / \lambda_{\mathrm{em}}=350$ $\mathrm{nm} / 460 \mathrm{~nm}$. The effect of micelle medium on the fluorescence emission was studied which revealed that the anionic surfactant of sodium lauryl sulphate has strong sensitizing effect for the fluorescence. The fluorescence intensity plot was linear over the range of $0.1-3.6 \mu \mathrm{g} / \mathrm{ml}$ with mean percentage recovery of $100.39 \pm 1.12 \%$. Determination was also successful when analyzing zaleplon in a formulation in the form of Siesta capsules. Results were statistically analyzed and found to be in accordance with those given by a reported method.
\end{abstract}

Keywords: Zaleplon; Stability indicating; Densitometric; Spectrofluorimetric; Acidic degradations

\section{Introduction}

Zaleplon is a sedative hypnotic of the pyrazolopyrimidine class with a chemical name of $\mathrm{N}$-[3-(3-cyanopyrazolo $\{1,5-\mathrm{a}\}$ pyrimidine-7yl) phenyl]-N-ethylacetamide (Figure 1). It has an empirical formula of $\mathrm{C}_{17} \mathrm{H}_{15} \mathrm{~N}_{5} \mathrm{O}$ and a molecular weight of $305.34 \mathrm{~g} / \mathrm{mol}$ [1]. It is chemically unrelated to the benzodiazepine class of medications for sleep, but it has similar effects. It is extensively metabolized into 5-oxo zaleplon and 5-oxo desethyl zaleplon. Zaleplon interacts with GABA receptor complex and shares some of the pharmacological properties of the benzodiazepines [2]. Moreover, zaleplon has the ability to shorten sleep latency, promote the maintenance of sleep, and increase slow wave sleep in the early phases as seen in polysomnographic studies in humans [3].

The literature survey reveals several methods for determination of Zaleplon in plasma [4-9], hair and oral fluids [10,11], blood [12$14]$, human urine [15] and in postmortem specimen [1,16]. It was also determined in capsules by voltammetric method [17] and in tablets by<smiles>CCN(C(C)=O)c1cccc(-c2ccnc3c(C#N)cnn23)c1</smiles>

Figure 1: Structural formula of zaleplon reversed phase high performance liquid chromatographic (RP-HPLC) method [18]. It is worth noting that only one spectrofluorimetric technique was reported for its determination in micellar medium, which established as a non stability indicating method [19]. It was determined in presence of its impurities and degradation products by HPLC method only [2]. A spectrophotometric, densitometric and HPLC methods were adopted for its determination in pharmaceutical preparations as stability indicating methods only with its alkaline degradations [20].

The scientific novelty of the present work is that all the previously mentioned methods didn't prove to determine zaleplon in presence of its acidic degradations. So, in the present work, two simple, selective, and validated methods of densitometry and spectrofluorimetry were developed to quantify the drug in its pure form, in a pharmaceutical formulation, and in mixtures with its acidic degradation products.

\section{Experimental}

\section{Apparatus}

1. Shimadzu densitometer- dual wave length flying spot (CS9301, Tokyo, Japan).

2. Thin layer chromatographic plates precoated with silica gel $\mathrm{GF}_{254},(10 \times 20) \mathrm{cm}$ (Fluka, Switzerland ).

*Corresponding author: Amal S Mohamed, National Organization for Drug Control and Research (NODCAR), 6 Abu Hazem Street, Pyramids Ave. P. O. Box 29.Giza, Egypt, E-mail: Amal.saeed84@yahoo.com

Received May 31, 2013; Accepted June 26, 2013; Published June 28, 2013

Citation: Abdel Razeq SA, Soliman SM, Mohamed AS (2013) Development of Stability Indicating Densitometric and Enhanced Sensitivity Spectrofluorimetric Methods for Determination of Zaleplon in Presence of its Acidic Degradation Products. Pharm Anal Acta 4: 256. doi:10.4172/2153-2435.1000256

Copyright: () 2013 Abdel Razeq SA, et al. This is an open-access article distributed under the terms of the Creative Commons Attribution License, which permits unrestricted use, distribution, and reproduction in any medium, provided the original author and source are credited. 
Citation: Abdel Razeq SA, Soliman SM, Mohamed AS (2013) Development of Stability Indicating Densitometric and Enhanced Sensitivity Spectrofluorimetric Methods for Determination of Zaleplon in Presence of its Acidic Degradation Products. Pharm Anal Acta 4: 256. doi:10.4172/2153-2435.1000256

Page 2 of 7

3. $100 \mu \mathrm{l}$ Hamilton microsyringe (Germany).

4. UV lamp with short wave length $245 \mathrm{~nm}$. (Desaga-Germany).

5. Shimadzu Spectrofluorometer (RF-1501, Tokyo, Japan) equipped with xenon lamp and 1-cm glass cells.

\section{Materials}

Authentic sample: Zaleplon (B.N.20103201p) was kindly supplied by $\mathrm{Al}$-Andalous medical Company. Its purity was found to be $99.3 \%$ as referred by the supplier.

Dosage form: Siesta ${ }^{\circledR}$ capsules (Batch No. 50507), labeled to contain $10 \mathrm{mg}$ Zaleplon is from SIGMA For Al Andalous Medical Company, Cairo, Egypt.

\section{Chemicals and solvents}

- Ethanol, cetrimid and ethyl acetate (Sigma Aldrich. St. Louis. USA), methanol and ammonia 33\% (El Nasr Pharmaceutical Chemicals Co. Egypt), hydrochloric acid (Aldrich, Germany), sodium hydroxide (Winlab, France); $6 \mathrm{~N}$ solutions prepared in water, sulphuric acid (Adwic Co, Egypt), cetylpyridinium bromide (Prolabo, Egypt), tween 40, tween 80 (Aldrich, Egypt), triton TX-100 (aMRGSCO, Co., Egypt), sodium lauryl sulphate (BHD, Egypt) and $\beta$-cyclodextrin (Deltapharma).

- Deionised water (SEDICO pharmaceuticals Co., Cairo, Egypt).

N.B.: All the chemicals were of analytical grade. The solvents used for the spectrodensitometric method were of spectrophotometric grade.

\section{Standard Preparations}

\section{Stock solutions}

Stock standard solution for spectrodensitometric and spectrofluorimetric methods: Stock solution of zaleplon was prepared by weighing accurately $100 \mathrm{mg}$ of pure powder, transferring into two separate 100 -ml volumetric flasks, adding $20 \mathrm{ml}$ ethanol, shaking well then completing to the mark with the same solvent to get $1000 \mu \mathrm{g} / \mathrm{ml}$ stock solution for each

Stock standard solution of acidic degradates: $100 \mathrm{mg}$ zaleplon powder were accurately weighed and transferred into $250 \mathrm{ml}$ round flask, dissolved in $20 \mathrm{ml}$ ethanol then refluxed with $100 \mathrm{ml} 6 \mathrm{~N}$ hydrochloric acid for 12 hours. After cooling, the solution was adjusted to $\mathrm{pH}$ 7-8 with $6 \mathrm{~N}$ sodium hydroxide and evaporated to dryness under vacuum. The residues were then extracted with ethanol $(3 \times 20 \mathrm{ml})$, filtered into 100 -ml volumetric flask and completed to volume with ethanol to get $1000 \mu \mathrm{g} / \mathrm{ml}$ stock solution for each. The degradates were separated in pure form by preparative normal phase column chromatography using silica gel as a stationary phase and ethyl acetate: methanol: amm. 33\% $(8.5: 1: 0.5 \mathrm{v} / \mathrm{v} / \mathrm{v})$ as a mobile phase. Degradate fractions were collected together and allowed to dry at room temperature until constant weight. The dry powder was identified by IR (Figure 2).

\section{Working solutions}

For spectrodensitometric method: Ten milliliters of each of zaleplon and the degradates were separately transferred into separate $100 \mathrm{ml}$ volumetric flasks, completed to the mark with ethanol to get 100 $\mu \mathrm{g} / \mathrm{ml}$ working solutions.

For spectrofluorimetric method: One milliliter of each of zaleplon and its degradates were separately transferred into three separate 100 $\mathrm{ml}$ volumetric flasks, completed to the mark with ethanol to get $10 \mu \mathrm{g} /$ $\mathrm{ml}$ working solutions.

\section{Procedure}

\section{Spectrodensitometric method}

Linearity and construction of calibration curve: Accurate aliquots equivalent to $(0.5-2.5 \mu \mathrm{g} / \mathrm{spot})$ of zaleplon working solutions were applied on precoated $10 \times 20 \mathrm{~cm}$ TLC aluminum sheet silica gel $\mathrm{F}_{254}$ plates using Hamilton micro-syringe $(100 \mu \mathrm{l})$. Plates were spotted $1.5 \mathrm{~cm}$ apart from each other and $2 \mathrm{~cm}$ apart from the bottom edge. The chromatographic chamber was pre-saturated for 30 minutes with the mobile phase, then developed by ascending chromatography with ethyl acetate : methanol : ammonia $33 \%(8.5: 1: 0.5 \mathrm{v} / \mathrm{v} / \mathrm{v})$ as a mobile phase through a distance of $7 \mathrm{~cm}$ at room temperature. The plates were air dried and detected under UV lamp $(245 \mathrm{~nm})$. The calibration curve was constructed by plotting the area under the peak versus the corresponding drug concentrations in $\mu \mathrm{g} / \mathrm{spot}$ and the regression equation was developed.

Analysis of laboratory prepared mixtures: The peak heights of different laboratory prepared mixtures containing different ratios of zaleplon and the degradates were measured and the concentration of zaleplon in each mixture was obtained by applying in the corresponding regression equation.

\section{Spectrofluorimetric method}

Linearity and construction of calibration curve: Aliquots of working ethanolic solution equivalent to $(0.1-3.6 \mu \mathrm{g} / \mathrm{ml})$ were separately transferred into a series of $25-\mathrm{ml}$ volumetric flasks, followed by adding $8 \mathrm{ml} \mathrm{3 \%}$ SLS and diluted to the volume with water. The fluorescence intensity was measured at $\lambda_{\text {em }} 460 \mathrm{~nm}$ using $\lambda_{\mathrm{ex}} 350 \mathrm{~nm}$. Calibration curve was constructed by plotting the fluorescence intensity versus the corresponding drug concentrations in $\mu \mathrm{g} / \mathrm{ml}$ and the regression equation was computed.

Analysis of laboratory prepared mixtures: The fluorescence intensity of different laboratory prepared mixtures containing different ratios of zaleplon and the degradates were measured and the concentration of zaleplon in each mixture was obtained by applying in the corresponding regression equation.

\section{Application to pharmaceutical formulation}

The content of 5 capsules of Siesta ${ }^{\circledR}$ capsules each contains 10 mg zaleplon were emptied and mixed well, transferred into $50-\mathrm{ml}$ volumetric flask, $25 \mathrm{ml}$ ethanol were added, then centrifuged for about $30 \mathrm{~min}$, filtered, then completed to the volume to get $1000 \mu \mathrm{g} /$ $\mathrm{ml}$ stock solution. Then as mentioned in details under each method, appropriate working solutions were prepared, linearity procedure was followed and the drug concentrations were calculated from the corresponding regression equations. The validity of the method was assessed through applying the standard addition technique by mixing different concentrations of the standard drug to a fixed amount of its formulation. The concentrations of standard added were calculated from the corresponding regression equations.

\section{Results and Discussion}

As zaleplon is susceptible to acidic degradation being contains the nitril group which is liable to hydrolysis in presence of thermal conditions, so far the techniques in this manuscript are adopted to be stability indicating methods. Upon degradation of zaleplon with $6 \mathrm{M}$ $\mathrm{HCl}$ for $12 \mathrm{hrs}$, the interpretation of the IR spectrum of zaleplon and its acidic degradates (Figure $2 \mathrm{a}$ and $2 \mathrm{~b}$ ) revealed that the peak of cyanide group which appeared in the drug at $2230 \mathrm{~cm}^{-1}$ disappeared and a new 
Citation: Abdel Razeq SA, Soliman SM, Mohamed AS (2013) Development of Stability Indicating Densitometric and Enhanced Sensitivity Spectrofluorimetric Methods for Determination of Zaleplon in Presence of its Acidic Degradation Products. Pharm Anal Acta 4: 256. doi:10.4172/2153-2435.1000256

Page 3 of 7

one at $3428 \mathrm{~cm}^{-1}$ appeared indicating the presence of hydroxyl group in addition to the appearance of strong absorption band at 1735 that corresponding to carbonyl of carboxylic group. Also the peak of carbonyl group that presents in the parent compound at $1649 \mathrm{~cm}^{-1}$ was disappeared indicating that the amide group was broken and instead of, a broad band that corresponding to amide $\mathrm{NH}$ group at 3271 was appeared. The proposed mechanism of degradation reaction is illustrated in (Figure 3).

\section{Spectrodensitometric method}

This technique is based on the differences in $\mathrm{R}_{\mathrm{f}}$ values of zaleplon (0.79), and its acidic degradates (0.52), offering a simple way for quantification of zaleplon directly by measuring the optical density of the separated bands (Figure 4). By applying the method, a linear correlation was obtained between the area under the peak and the concentration in the range of $0.5-2.5 \mu \mathrm{g} / \mathrm{spot}$, from which the linear regression equation was calculated (Figure 5).

Optimization of spectrodensitometric method: The experimental conditions for the TLC method were optimized to provide accurate, precise, and reproducible results for the determination of zaleplon in the presence of its [21] acidic degradation products. The scan mode chosen was the zigzag mode and swing width was $10 \mathrm{~mm}$. Different scanning wavelengths were tried but the best sensitivity was at $338 \mathrm{~nm}$ .Also by studying different developing systems with different ratios, the most suitable one with good $\mathrm{R}_{\mathrm{f}}$ values was ethyl acetate-methanolammonia (33\%) (8.5:1:0.5v/v/v).

\section{Spectrofluorimetric method}

Zaleplon showed native fluorescence at $\lambda_{\mathrm{em}}=460$ after being excited

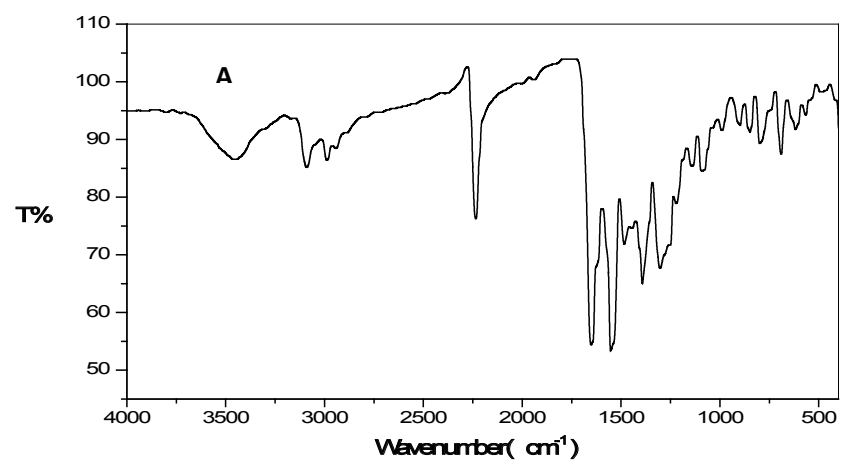

Figure 2a: IR of zaleplon.

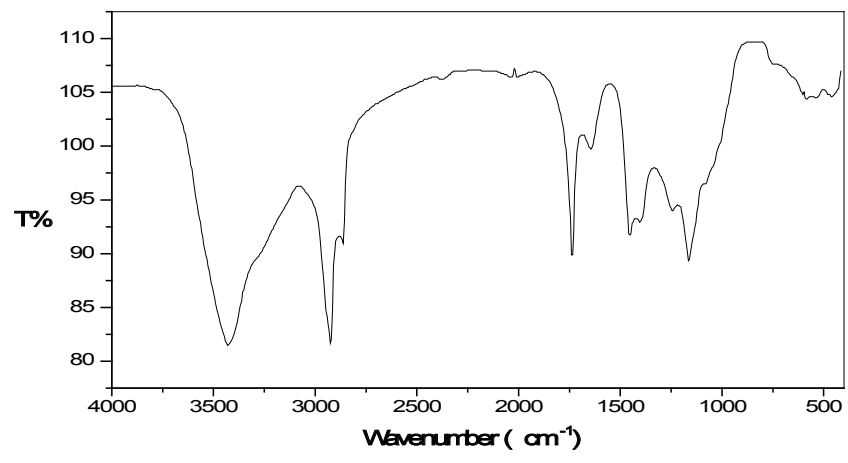

Figure $\mathbf{2 b}$ : IR of acidic degradates of zaleplon.

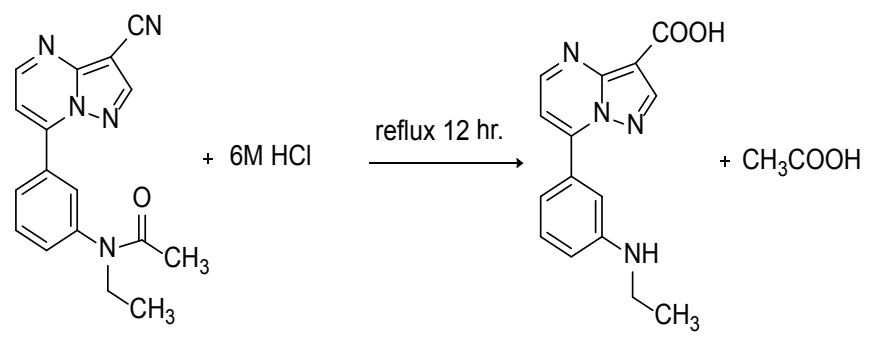

Figure 3: Proposal of acidic degradation pathway.

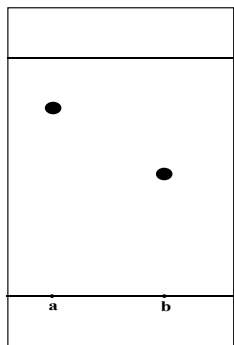

Figure 4: Thin layer chromatogram of (a) intact zaleplon and (b) acidic degradates.

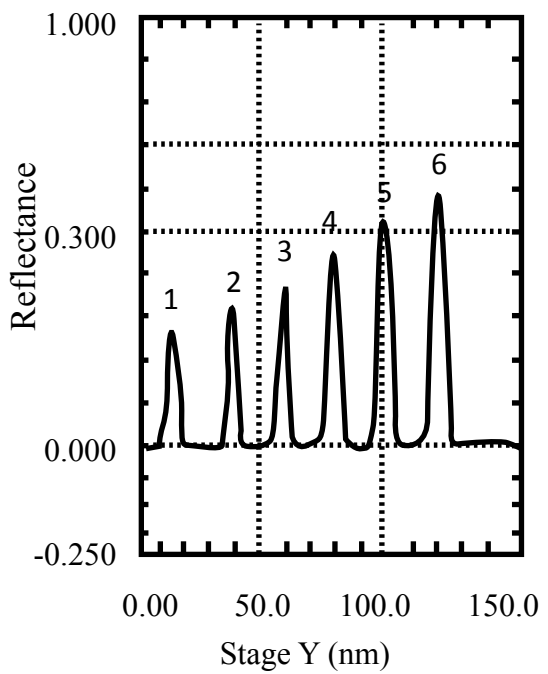

Figure 5: Densitometric chromatogram of zaleplon $(0.5-2.5 \mu \mathrm{g} / \mathrm{spot})$ at 338 $\mathrm{nm}$.

at $\lambda_{\mathrm{ex}}=360$. This fluorescence intensity was increased extensively upon using SLS (anionic surfactant) (Figure 6). The method proved to be stability indicating method as the degradation products do not exhibited native fluorescence [21]. By applying the method, a linear correlation was obtained between the fluorescence intensity and the concentration in the range of $0.1-3.6 \mu \mathrm{g} / \mathrm{ml}$, from which the linear regression equation was calculated (Figure 7).

\section{Optimization of spectrofluorimetric method}

Effect of different diluting solvents: Zaleplon showed native fluorescence signal in ethanol. Different solvents were tested to obtain 
Citation: Abdel Razeq SA, Soliman SM, Mohamed AS (2013) Development of Stability Indicating Densitometric and Enhanced Sensitivity Spectrofluorimetric Methods for Determination of Zaleplon in Presence of its Acidic Degradation Products. Pharm Anal Acta 4: 256. doi:10.4172/2153-2435.1000256

the high relative fluorescence intensity [22]. It was found that the higher fluorescence is in order ethanol $>$ methanol $>$ water $>$ aqueous alkali> aqueous acid, hence ethanol was the solvent of choice in this work (Figure 8).

Effect of micellar medium: The influence of micellar medium on the fluorescence intensity of zaleplon is studied by preparing $2 \mu \mathrm{g} / \mathrm{ml}$ solutions each with $1 \mathrm{ml}$ of $1 \%$ surfactants in aqueous media. It proved that the anionic surfactant of SLS enhanced the fluorescent intensity of zaleplon much more than other surfactants. The enhancement was due to the following reasons: zaleplon is a nitrogen-ring compound whose alkalinity is stronger when excited than in the ground state. So zaleplon dramatically inclined to form hydrogen bonds with water in the excited state to cause zaleplon molecules exposed to the oxygen, the fluorescence quencher dissolved in water, hence the fluorescence quenching occurred. With the surfactant added, zaleplon was enriched into micellar assemblies and the protective microenvironment offered by the micellar medium can shield the excited singlet state of zaleplon from intermolecular collisional quenching and non radiative decay process occurring. Also the fluorescence quenching caused by dissolved oxygen was prevented [19]. Moreover, as the anionic surfactant SLS has four oxygen atoms; it can easily form hydrogen bonds with zaleplon. These hydrogen bonds not only prevented the formation of hydrogen bonds between zaleplon and water, but also produce electron donating effect, which can strengthen the delocalization effect of electrons in conjugated system and therefore the fluorescence increased. The enhancement ability sequence is shown in Figure 9.

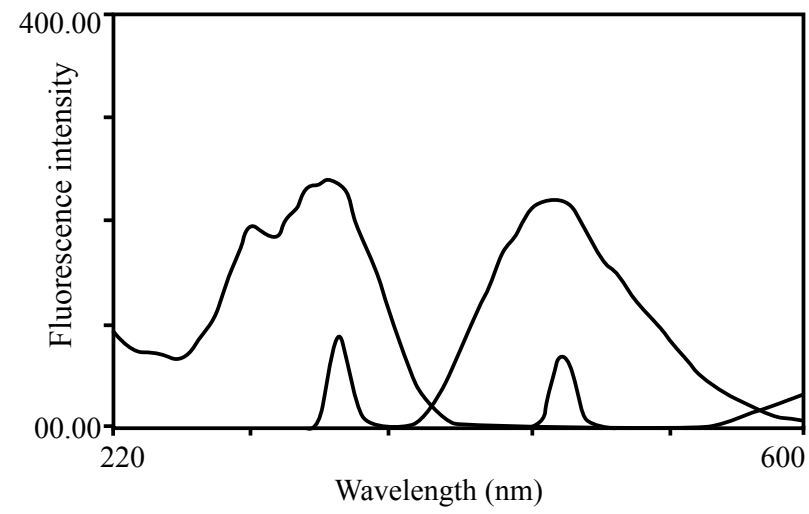

Figure 6: Excitation and emission spectra of $2 \mu \mathrm{g} / \mathrm{ml}$ of Zaleplon at $\lambda_{\mathrm{ex}} / \lambda_{\mathrm{em}}=$ $350 \mathrm{~nm} / 460 \mathrm{~nm}$ in micelle media.

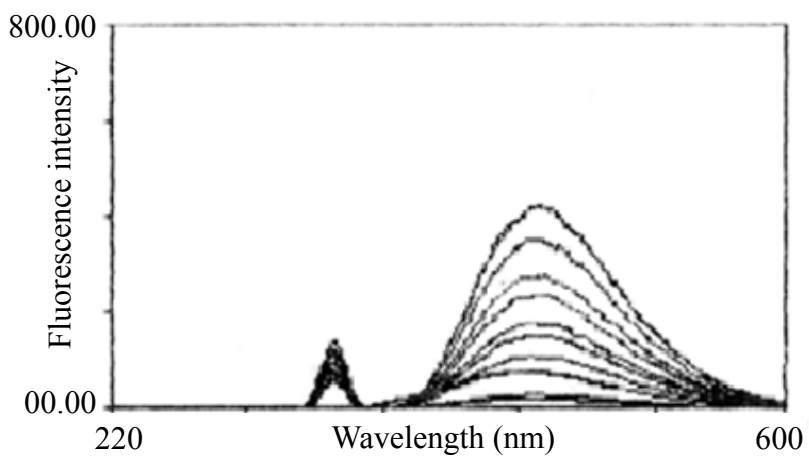

Figure 7: Emission Spectra of calibration set 0.1-3.6 $\mu \mathrm{g} / \mathrm{ml}$ zaleplon at $460 \mathrm{~nm}$.

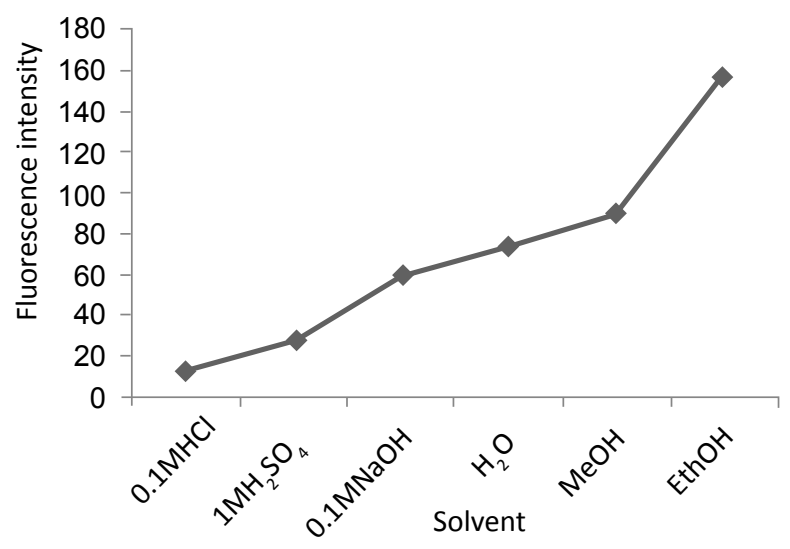

Figure 8: Effect of solvent on the fluorescence intensity of zaleplon $2 \mu \mathrm{g} / \mathrm{ml}$.

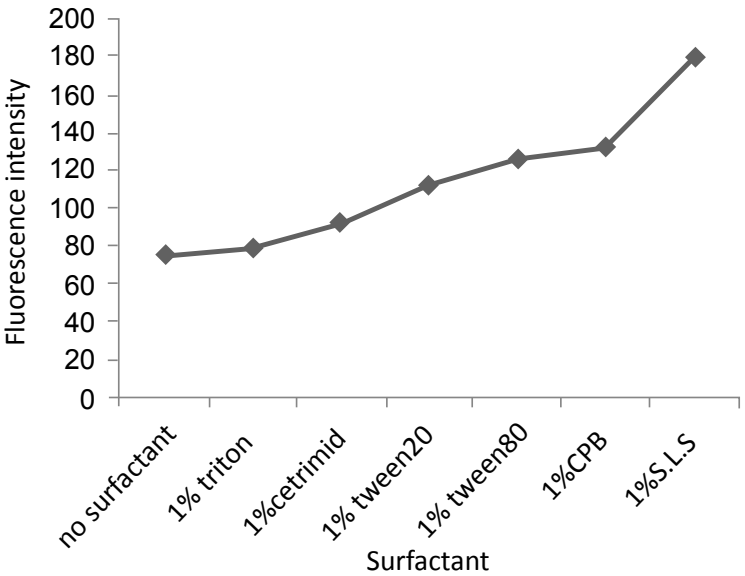

Figure 9: Effect of surfactant on the fluorescence intensity of zaleplon $2 \mu \mathrm{g} /$ $\mathrm{ml}$.

Effect of amount of SLS: Influence of amounts of SLS on fluorescence intensity of zaleplon was studied. The fluorescence intensity was high and relatively stable over the volume $8 \mathrm{ml}$ of 3\%SLS (Figure 10).

Effect of temperature: With temperature increasing the fluorescence intensity decreased, so this work was set throughout room temperature.

Effect of B-cyclodextrin: The influence of $\beta$-cyclodextrin on the fluorescence intensity of zaleplon is studied. By adding different increasing volumes, it proved that $8 \mathrm{ml}$ of $1 \% \mathrm{w} / \mathrm{v} \beta$-cyclodextrin enhanced the fluorescent intensity of zaleplon but not more than that of SLS. Thus SLS was the sensitizer of choice in this work (Figure 11).

Effect of metal: Upon addition of $\mathrm{FeCl}_{3} 0.5 \%, \mathrm{AlCl}_{3} 1.33 \%$, $\mathrm{ZnSO}_{4} 1.5 \%$ and $\mathrm{Cu}$ acetate $10^{-2} \mathrm{M}$; no any complex formed and as a result of that no any change in fluorescence.

Effect of 3-methylbenzothiazolin-2-one hydrazone hydrochloride in the presence of cerium (IV) ammonium sulfate in an acidic medium: Upon addition of $1.5 \mathrm{ml} 0.2 \% \mathrm{MBTH}$ and 1.5 $\mathrm{ml} 1 \%$ cerium (IV) ammonium sulfate in presence of $1 \mathrm{~N}$ sulfuric acid; no oxidative coupling reaction occurred and as a result of that no any quenching effect on the cerium fluorescence. 
Citation: Abdel Razeq SA, Soliman SM, Mohamed AS (2013) Development of Stability Indicating Densitometric and Enhanced Sensitivity Spectrofluorimetric Methods for Determination of Zaleplon in Presence of its Acidic Degradation Products. Pharm Anal Acta 4: 256. doi:10.4172/2153-2435.1000256

Page 5 of 7

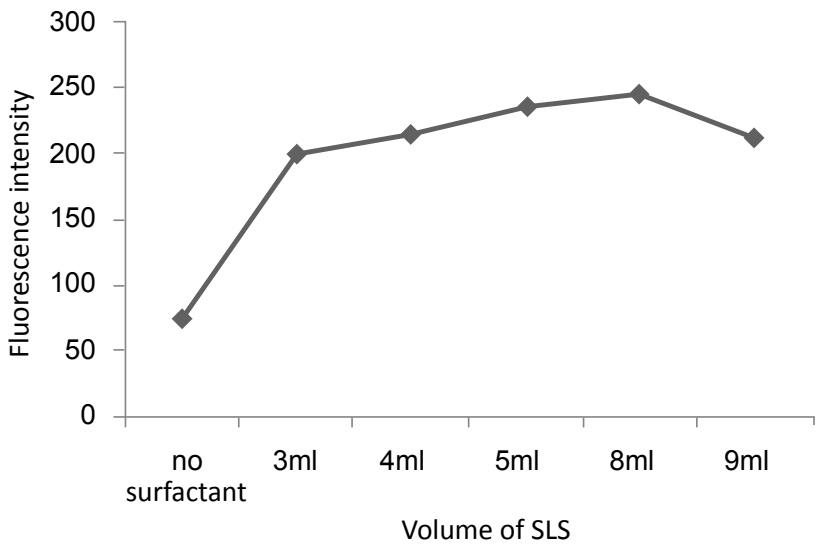

Figure 10: Influence of the volume of SLS surfactant on fluorescence intensity of zaleplon $2 \mu \mathrm{g} / \mathrm{ml}$

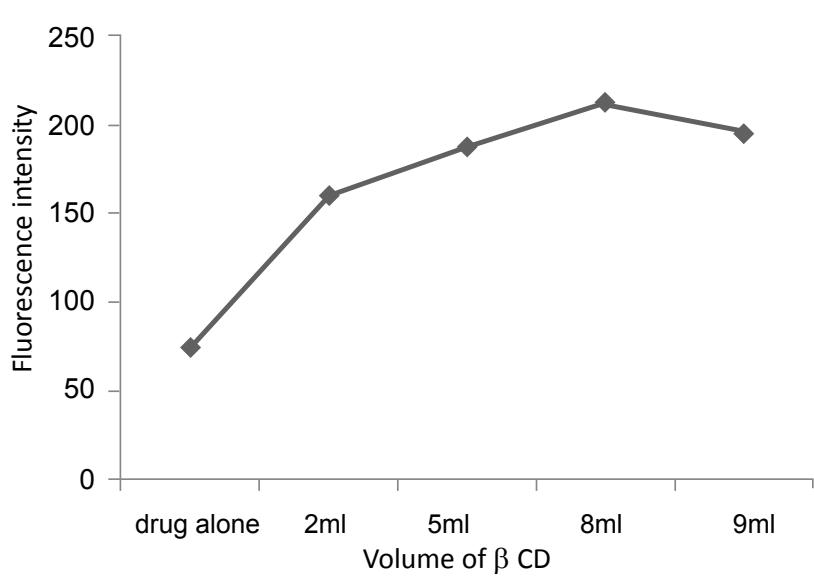

Figure 11: Influence of $\beta C D$ on fluorescence intensity of zaleplon $2 \mu \mathrm{g} / \mathrm{ml}$

Effect of gelatin: Hopefully gelatin may enhance the fluorescence intensity of some compounds, but unfortunately, it was found that it had no any sensitizing effect on zaleplon fluorescence.

Quenching effect of zaleplon on Uranyl acetate fluorescence: Uranyl acetate showed fluorescence at $509 \mathrm{~nm}$ after excitation at 305 $\mathrm{nm}$. Zaleplon has a so little quenching effect on this fluorescence, thus there is no need to use it.

\section{Method validation}

Linearity: The proposed methods showed a linear correlation between peak under the area in densitometric method and drug concentration in the range of $0.5-2.5 \mu \mathrm{g} / \mathrm{spot}$. With the spectrofluorimetric method, linearity between fluorescence intensity and drug concentration over the range of $0.1-3.6 \mu \mathrm{g} / \mathrm{ml}$ was obtained. The high value of correlation coefficient assured the validity of the method and its coinciding with Beer's law system as showed with other regression parameters in Table 1.

Accuracy and precision: The proposed methods showed good repeatability when applied to pure zaleplon over three concentration levels $(0.5,1.5,2.5)$ for densitometric method and $(0.1,1.6,3.6)$ for fluorimetric method to estimate intra-day variation as shown in Table 1.

Reproducibility of the methods was indicated by applying the proposed methods over the previous concentration levels in 3 different days. The relative standard deviations were less than $2.0 \%$ indicating good precision Table 1 .

Specificity: Laboratory prepared mixtures containing the intact drug and its degradation products in different proportions were analyzed. The data indicated the validity of the methods for determination of zaleplon in presence of up to $80-97.2 \%$ of acidic degradations without any interference. Good recovery and RSD \% indicated that the methods are stability indicating Table 2.

Specificity of the methods was further assured by successful application for analysis of the drug in its pharmaceutical formulation (Siesta ${ }^{\circledR}$ capsules). The satisfactory results were statistically compared with those obtained by the reported method from the supplier company. As shown in Table 3, calculated t- and $F$ - values were less than tabulated ones, indicating no significant difference with respect to accuracy and precision.

Validity of the proposed methods was more assessed using the standard addition technique by adding known different amounts of pure zaleplon to a known concentration of the capsules. The good recoveries assured the accuracy of the methods Table 4 .

Detection and quantification limits: The detection limit (LOD) was defined as the concentration of drug giving a signal to noise ratio of 3:1 and LOQ was estimated using the 106 criterion $[23,24]$. The obtained results were listed in Table 1.

Stability: Working solutions of zaleplon showed no spectrofluorimetric or chromatographic changes through 4 days when kept stored in refrigerator.

\section{Conclusion}

The proposed spectrodensitometric and spectro-fluorimetric methods are accurate, sensitive and selective methods. They allow the determination of zaleplon in pure form, in the presence of its acidic degradation products, as well as in pharmaceutical dosage form. The methods can be applied simply for routine analysis in quality control testing and drug stability monitoring. Moreover, they offer fast response and low cost.

\begin{tabular}{|c|c|c|}
\hline parameters & TLC-method & Fluorimetric method \\
\hline Linearity range & $0.5-2.5 \mu \mathrm{g} / \mathrm{spot}$ & $0.1-3.6 \mu \mathrm{g} / \mathrm{ml}$ \\
\hline Accuracy Mean \pm RSD $\%$ & $100.79 \pm 0.65 \%$ & $100.39 \pm 1.12$ \\
\hline $\begin{array}{l}\text { Precision }(n=9) \text { Mean } \pm \text { RSD } \% \\
\text { alntraday }\end{array}$ & $99.92 \pm 0.44$ & $100.29 \pm 0.44$ \\
\hline bInterday & $100.65 \pm 0.95$ & $100.03 \pm 1.07$ \\
\hline $\begin{array}{l}\text { Regression parameters } \\
\text { a Slope } \pm \text { SE }\end{array}$ & $1249 \pm 16.91$ & $115.2 \pm 0.58$ \\
\hline${ }^{\mathrm{b}}$ Intercept \pm SE & $728.8 \pm 30.86$ & $18.10 \pm 1.43$ \\
\hline $\begin{array}{l}\text { c Correlation coefficient } \pm \text { SE of } \\
\text { estimation }\end{array}$ & $0.9994 \pm 20.07$ & $0.9995 \pm 1.26$ \\
\hline LOD & 0.001 & 0.013 \\
\hline LOQ & 0.003 & 0.038 \\
\hline
\end{tabular}

Table 1: Regression parameters and method validation results obtained by applying the proposed methods for determination of zaleplon. 
Citation: Abdel Razeq SA, Soliman SM, Mohamed AS (2013) Development of Stability Indicating Densitometric and Enhanced Sensitivity Spectrofluorimetric Methods for Determination of Zaleplon in Presence of its Acidic Degradation Products. Pharm Anal Acta 4: 256. doi:10.4172/2153-2435.1000256

Page 6 of 7

\begin{tabular}{|c|c|c|c|c|c|}
\hline \multicolumn{3}{|c|}{ Densitometric method } & \multicolumn{3}{|c|}{ Spectrofluorimetric method } \\
\hline Intact ( $\mu \mathrm{g} / \mathrm{spot})$ & Degradations ( $\mu \mathrm{g} / \mathrm{spot})$ & $\mathrm{R} \%$ ( $\mu \mathrm{g} / \mathrm{spot})$ & Intact $(\mu \mathrm{g} / \mathrm{spot})$ & Degradations ( $\mu \mathrm{g} / \mathrm{spot})$ & $\mathrm{R} \%(\mu \mathrm{g} / \mathrm{spot})$ \\
\hline 2.4 & 0.1 & 99.1 & 3.2 & 0.4 & 100.5 \\
\hline 2.1 & 0.4 & 99.03 & 2.8 & 0.8 & 100.6 \\
\hline 1.5 & 0.5 & 100.5 & 2 & 1.6 & 100.8 \\
\hline 1.2 & 1.3 & 99.6 & 0.8 & 2.8 & 100.1 \\
\hline 0.9 & 1.6 & 100.9 & 0.4 & 3.2 & 100.9 \\
\hline 0.5 & 2 & 101.4 & 0.1 & 3.5 & 101.7 \\
\hline Mean $\pm S D$ & \multicolumn{2}{|c|}{$100.29 \pm 0.96$} & Mean \pm SD & \multicolumn{2}{|c|}{$100.77 \pm 0.54$} \\
\hline
\end{tabular}

Table 2: Determination of zaleplon in mixtures with its acidic degradation products by the proposed methods.

\begin{tabular}{|c|c|c|c|}
\hline Parameters & Densitometric method & Fluorimetric method \\
\hline Mean \% & 99.07 & 100.04 \\
\hline SD & 0.57 & 0.99 \\
\hline Variance & 0.33 & 0.98 & 98.9 \\
\hline N & 5 & 5 & 1.02 \\
\hline$t$-test $(2.31)^{\mathrm{b}}$ & 0.33 & 5 & 1.05 \\
\hline F-test $(6.39)^{\mathrm{b}}$ & 3.15 & 1.06 & \\
\hline
\end{tabular}

aReference method is the company method, ${ }^{\mathrm{b}}$ Figures in parenthesis are the theoretical values of $t$ and $F$ at $\mathrm{p}=0.05$

Table 3: Statistical analysis of the result obtained by the proposed procedures and reported procedure for the determination of zaleplon in its pharmaceutical formulation.

\begin{tabular}{|c|c|c|c|c|c|}
\hline \multicolumn{3}{|c|}{ Densitometric method } & \multicolumn{3}{|c|}{ Fluorimetric method } \\
\hline Claimed taken & Pure added & $\mathrm{R} \%$ of added & Claimed taken & Pure added & $\mathrm{R} \%$ of added \\
\hline \multirow{4}{*}{0.7} & 0.7 & 99.81 & \multirow{4}{*}{1.2} & 0.6 & 101.53 \\
\hline & 1 & 101.45 & & 0.8 & 99.04 \\
\hline & 1.4 & 100.42 & & 1.2 & 100.07 \\
\hline & 1.8 & 99.13 & & 2.4 & 100.04 \\
\hline \multicolumn{2}{|c|}{ Mean $\pm S D$} & $100.2 \pm 0.9$ & \multicolumn{3}{|c|}{$100.17 \pm 1.02$} \\
\hline
\end{tabular}

Table 4: Application of standard addition technique for the determination of zaleplon in its pharmaceutical preparation by the proposed methods.

\section{References}

1. Anderson DT, Budd RD (2009) Zaleplon (Sonata) analysis in postmortem specimens by gas chromatography-electron capture detection. J Anal Toxicol 33: $481-485$

2. Rashmith N, Sharma HK, Mukkanti K (2012) Development of stability indicating HPLC method for the determination of impurities in zaleplon. J Research Pharm Biomed Sci 3: 1424-1431.

3. Walsh JK, Fry J, Erwin CW, Scharf M, Roth T, et al. (1998) Efficacy and tolerability of 14-days administration of zaleplon $5 \mathrm{mg}$ and $10 \mathrm{mg}$ for the treatment of primary insomnia. Clin Drug Invest 16: 347-354.

4. Kratzsch C, Tenberken O, Peters FT, Weber AA, Kramer T, et al. (2004) Screening, library-assisted identification and validated quantification of 23 benzodiazepines, flumazenil, zaleplone, zolpidem and zopiclone in plasma by liquid chromatography/mass spectrometry with atmospheric pressure chemical ionization. J Mass Spectrom 39: 856-372.

5. Feng F, Jiang J, Dai H, Wu J (2003) Development and validation of a highperformance liquid chromatography-electrospray ionization-mass spectrometry assay for the determination of zaleplon in human plasma. J Chromatogr Sci 41: 17-21.

6. Zhang B, Zhang Z, Tian Y, Xu F, Chen Y (2006) High-performance liquid chromatography-atmospheric pressure chemical ionisation-mass spectrometry determination of zaleplon in human plasma. J Pharm Biomed Anal 40: 707-714.

7. Ming D, Sufen Z, Jianfang L, Huichen L (2004) Determination of Zaleplon in Human Plasma by RP - HPLC with Fluorescence Detection. Yaowu Fenxi Zazhi 24: 611-613.

8. Foda NH, Elbary AA, El-Gasazyerly O (2006) Reversed-phase liquid chromatographic determination of zaleplon in human plasma and its pharmacokinetic application. J Anal Lett 39: 1891-1905.

9. Guocheng L, Junyan W, Rifang L (2003) Determination of zaleplon in blood plasma by RP-HPLC with fluorescence detection. Academic Journal of Guangdong collage of pharmacy 19: 322-324.
10. Villain M, Concheiro M, Cirimele V, Kintz P (2005) Screening method for benzodiazepines and hypnotics in hair at $\mathrm{pg} / \mathrm{mg}$ level by liquid chromatographymass spectrometry/mass spectrometry. J Chromatogr B Analyt Technol Biomed Life Sci 825: 72-78.

11. Kintz P, Villain M, Concheiro M, Cirimele V (2005) Screening and confirmatory method for benzodiazepines and hypnotics in oral fluid by LC-MS/MS. Forensic Sci Int 150: 213-220.

12. Gunnar T, Mykkanen S, Ariniemi K, Lillsunde P (2004) Validated semiquantitative/quantitative screening of 51 drugs in whole blood as silylated derivatives by gas chromatography-selected ion monitoring mass spectrometry and gas chromatography electron capture detection. J Chromatogr B Anal Technol Biomed Life Sci 806: 205-219.

13. Guannar T, Ariniemi K, Lillsunde P (2006) Fast gas chromatography-negativeion chemical ionization mass spectrometry with microscale volume sample preparation for the determination of benzodiazepines and alpha-hydroxy metabolites, zaleplon and zopiclone in whole blood. J Mass Spectrom 41: 741 754.

14. Giroud C, Augsburger M, Menetrey A, Mangin P (2003) Determination of zaleplon and zolpidem by liquid chromatography-turbo-ionspray mass spectrometry: application to forensic cases. J Chromatogr B Analyt Techno Biomed Life Sci 789: 131-138.

15. Horstkötter C, Schepmann D, Blaschke G (2003) Separation and identification of zaleplon metabolites in human urine using capillary electrophoresis with laser-induced fluorescence detection and liquid chromatography-mass spectrometry. J Chromatogr A 1014: 71-81.

16. Crifasi JA, Bruder MF, Long CW, Janssen K (2006) Performance evaluation of thermal desorption system (TDS) for detection of basic drugs in forensic samples by GC-MS. J Anal Toxicol 30: 581-592.

17. Larenas G, Bollo S, Rodriguez M, Lemus I, Nuñez-Vergara LJ, et al. (2005) Voltammetric behavior of zaleplon and its differential pulse polarographic determination in capsules. J AOAC Int 88: 1135-1141.

18. Rao TN, Srineevasula REG, Patrudu TB, Parvathamma T (2012) Estimation of zaleplon by a new RP-HPLC method. J Chem Pharm Research 4: 3010-3014. 
Citation: Abdel Razeq SA, Soliman SM, Mohamed AS (2013) Development of Stability Indicating Densitometric and Enhanced Sensitivity Spectrofluorimetric Methods for Determination of Zaleplon in Presence of its Acidic Degradation Products. Pharm Anal Acta 4: 256. doi:10.4172/2153-2435.1000256

19. Tang B, Wang X, Jia BX, Niu YJ, Wei $Y$, et al. (2003) Simple, rapid, and sensitive spectrofluorimetric determination of zaleplon in micellar medium. Anal Lett 36: 2985-2997.

20. Metwally FH, Abdelkawy M, Abdelwahab NS (2007) Application of spectrophotometric, densitometric, and HPLC techniqes as stability indicating methods for determination of zaleplon in pharmaceutical preparations. J Spectrochem Acta 68: 1220-1230.

21. Salama NNA, Mohamed AO (2009) Stability-indicating methods for the determination of sertaconazole nitrate by micelle-enhanced spectrofluorimetry and TLC-densitometry. Bull Chem Soc Ethiop 23: 167-174.
22. Aiyub Z, Abdullah Z, Yaakob BH, Abu Bakar MA (2007) Fluorescence characteristic of 2-chloropyrazine: effect of solvents and concentration of $\mathrm{Cu}$ (ii) Malaysian J of Anal Sci 11: 105-109.

23. ICH Q2A (1994) Note for guidance on validation of analytical methods: definitions and terminology in IFPMA (ed): International Conference on Harmonization; Geneva.

24. ICH Q2B (1994) Note for guidance on validation of analytical procedure: Methodoloy in IFPMA(ed): International Conference on Harmonization Geneva. 